\title{
PTEN mutation, methylation and expression in breast cancer patients
}

\author{
HONG-YAN ZHANG $^{1 *}$, FENG LIANG $^{2 *}$, ZHI-LING JIA ${ }^{1}$, SAN-TAI SONG $^{3}$ and ZE-FEI JIANG ${ }^{3}$ \\ ${ }^{1}$ Department of Oncology, General Hospital of Beijing Military Area, Beijing 100700; Departments of ${ }^{2}$ General Surgery \\ and ${ }^{3}$ Breast Cancer, Affiliated Hospital of Academy of Military Medical Sciences, Beijing 100071, P.R. China
}

Received December 18, 2012; Accepted April 3, 2013

DOI: $10.3892 / \mathrm{ol} .2013 .1331$

\begin{abstract}
The tumor suppressor gene, PTEN, has previously been demonstrated to be involved in breast tumorigenesis and tumor progression. The aim of the present study was to investigate the expression and significance of PTEN in breast carcinomas, to detect the mutation frequency of PTEN in sporadic breast carcinoma tissues and to determine the association between PTEN promoter methylation and gene expression. Immunohistochemical methods were used to analyze the expression of the PTEN gene in 146 cases of breast carcinoma and 10 cases of normal breast tissue closely adjacent to the carcinoma. Polymerase chain reaction-single strand conformation polymorphism (PCR-SSCP) analysis was used to analyze conformation polymorphisms in 45 breast carcinoma and 10 normal breast tissues. Point mutations of abnormal single stranded conformation were detected by DNA sequencing. The methylation of the PTEN promoter was analyzed by methylation-specific PCR. Expression of PTEN was detected in $57.5 \%$ (84/146) of patients with breast carcinoma. By contrast, PTEN expression was detected in $100 \%$ of normal samples. Expression of PTEN was found to negatively correlate with the tumor size, the pathological stage and the expression of the estrogen receptor (ER) and the progesterone receptor (PR) in breast cancer. The 2-year disease-free survival of patients with a high expression of PTEN was higher compared with those with low PTEN expression $(\mathrm{P}<0.05)$. Missense mutations in exon 2 of PTEN were identified in $1 / 45$ breast cancer cases. PTEN promoter methylation was detected in $31.1 \%$ (14/45) of breast carcinomas, of which $64.3 \%(9 / 14)$ were associated with a loss of PTEN expression. The tumor suppressor gene, PTEN, was abnormally expressed in the breast carcinomas. The
\end{abstract}

Correspondence to: Dr Hong-yan Zhang, Department of Oncology, General Hospital of Beijing Military Area, No. 5 Nanmencang, Dongcheng, Beijing 100700, P.R. China

E-mail: roninzhy@126.com

${ }^{*}$ Contributed equally

Key words: PTEN gene, breast cancer, gene mutation, promoter methylation number of PTEN mutations were low (1/45) in the sporadic breast cancer cases analyzed in the present study and PTEN promoter methylation may have been the main mechanism leading to the decreased expression of PTEN. These results indicate that $P T E N$ is important for the tumorigenesis, development and prognosis of breast cancer.

\section{Introduction}

Breast cancer is the most common malignancy with a high mortality in females worldwide. Tumor suppressor genes are important for maintaining genome integrity and the cell cycle. PTEN was the first phosphatase to be identified as a tumor suppressor with diverse functions, including regulation of cell cycle, apoptosis and metastasis (1-4). Mutations or a reduced expression of the PTEN gene are associated with a wide variety of human tumors (5). Germline mutations in PTEN are known to cause Cowden syndrome (CS), which is characterized by a high risk of breast cancer. In families with CS, $\sim 80 \%$ have PTEN germline mutations and female CS patients have a $25-50 \%$ lifetime risk of developing breast cancer (6). In sporadic breast carcinomas, the frequency of PTEN loss is $30-40 \%$ and the somatic intragenic PTEN mutation frequency is $<5 \%$. Besides genetic change, aberrant DNA methylation is also responsible for the epigenetic silencing of genes associated with tumor genesis and progression of cancer. In the present study, the frequency of PTEN mutations, the methylation of PTEN and its association with the loss of PTEN expression were further investigated in sporadic breast carcinoma in a Chinese population.

\section{Material and methods}

Patients and tissue samples. A total of 146 female Chinese patients, who were diagnosed with breast cancer between 2003 and 2006, were included in the present study. Clinical and pathological information, including age, ethnicity, menopausal status, type of tumor, disease stage, axillary lymph nodes, tumor size and biomarkers, were collected. Paraffin blocks of tumor samples from all 146 patients and fresh frozen tumor specimens from 45 patients were prepared. In addition, 10 normal tissues adjacent to the tumors were also collected. All patients were followed up until December 2009. This study was approved by the ethics committee of the General 
Table I. PCR primers designed for 9 PTEN exons and MSP of PTEN

\begin{tabular}{llll}
\hline Primer & \multicolumn{1}{c}{ Sense (5'-3') } & \multicolumn{1}{c}{ Antisense (5'-3') } & bp \\
\hline Exon & & & \\
1 & TTCTGCCATCTCTCTCCTCC & ATCCGTCTACTCCCACGTTC & 194 \\
2 & GTTTGATTGCTGCATATTTCA & TCTAAATGAAAACACAACATGAA & 201 \\
3 & AGCTCATTTTGTTAATGGTGG & CCTCACTCTAACAAGCAGATAACTTTC & 178 \\
4 & AAAGATTCAGGCAATGTTTGTAG & TGACAGTAAGATACAGTCTATCGGG & 200 \\
$5-1$ & TTTTTTCTTATTCTGAGGTTATC & TCATTACACCAGTTCGTCC & 184 \\
$5-2$ & TCATGTTGCAGCAATTCAC & GAAGAGGAAAGGAAAAACATC & 176 \\
6 & ATGGCTACGACCCAGTTACC & AAGAAAACTGTTCCAATACATGG & 284 \\
7 & CAGTTAAAGGCATTTCCTGTG & GCTTTTAATCTGTCCTTATTTGG & 274 \\
$8-1$ & TTAACATAGGTGACAGATTTC & CACGCTCTATACTGCAAATG & 222 \\
$8-2$ & CATTCTTCATACCAGGACCAG & TGGAGAAAAGTATCGGTTGG & 188 \\
$8-3$ & GCATTTGCAGTATAGAGCGTG & TCAAGCAAGTTCTTCATCAGC & 217 \\
$9-1$ & AGATGAGTCATATTTGTGGG & CTCTGGATCAGAGTCAGTGG & 185 \\
$9-2$ & AATCCAGAGGCTAGCAGTTC & AAGGTCCATTTTCAGTTTATTC & 213 \\
MSP & & & 206 \\
Methylated & TTCGTTCGTCGTCGTATTT & GCCGCTTAACTCTAAACCGCAACCG & 162 \\
Unmethylated & GTGTTGGTGGAGGTAGTTGTTT & ACCACTTAACTCTAAACCACAACCA & \\
\hline
\end{tabular}

MSP, methylation-specific polymerase chain reaction.

Hospital of Beijing Military Area. Written informed consent was obtained from all patients.

Sample preparation. Tissue sections (thickness, 4-5 $\mu \mathrm{m}$ ) were cut from the paraffin blocks for the detection of PTEN expression in the breast carcinoma or normal breast tissues. Genomic DNA was isolated from frozen specimens using a NucleoSpin Tissue kit (Clontech, Mountain View, CA, USA) according to the manufacturer's instructions. DNA samples were frozen at $-70^{\circ} \mathrm{C}$ until use.

Immunohistochemistry. Following deparaffinization and dehydration in hydrogen peroxide, the sections were incubated at $37^{\circ} \mathrm{C}$ for $1 \mathrm{~h}$ with anti-PTEN mouse monoclonal antibody (1:25 dilution). Corresponding biotinylated anti-IgG was added and incubated for $30 \mathrm{~min}$ at $37^{\circ} \mathrm{C}$. Next, the sections were incubated with 3,3'-diaminobenzidine (DAB) substrate chromogen solution and counterstained with hematoxylin. Negative controls were incubated with phosphate-buffered saline (PBS) instead of primary antibody. Known positive tissues were used as positive controls. Immunohistochemical reactivity was graded according to the percentage of positive tumor cells: ,$- 0 ;+,<20 ;++, 20-50$; and,$+++>50 \%$. Grades - or + were considered as low level expression and grades ++ or +++ were considered as high level expression.

Analysis of PTEN gene mutation. Polymerase chain reaction-single strand conformation polymorphism (PCR-SSCP) analysis was performed to analyze mutations of the PTEN gene. The PTEN gene coding region was amplified from genomic DNA by PCR. Due to the low sensitivity of SSCP to detect sequences of $>300 \mathrm{bp}$, exons 5, 8 and 9 were ampli- fied separately. The oligonucleotide primer pairs located in exons 1-9 of the PTEN gene are listed in Table I. Following denaturation at $99^{\circ} \mathrm{C}$ for $10 \mathrm{~min}$, the PCR products were chilled on ice, followed by electrophoresis on a $8 \%$ polyacrylamide gel for $12 \mathrm{~h}$ at $40 \mathrm{~W}$. The gel was silver stained and the PCR products with aberrant bands or mobility shift were retrieved and sequenced directly.

Analysis of DNA methylation. Methylation of the PTEN promoter was assessed by bisulfite treatment. This lead to chemical conversion of any unmethylated cytosine to uracil, while the methylated cytosine remained unmodified. As described previously (7), methylation specific PCR (MSP) using 2 primer pairs was designed to distinguish methylated DNA from unmethylated DNA.

DNA modification by bisulfite treatment. The bisulfite conversion was performed using $1 \mu \mathrm{g}$ DNA. Briefly, the DNA was denatured by incubation with $10 \mu \mathrm{NaOH}(1 \mathrm{M})$ for $10 \mathrm{~min}$ at $37^{\circ} \mathrm{C}$. The samples were then treated with sodium bisulfite (3 M) and hydroquinone $(10 \mathrm{mM})$ for $16 \mathrm{~h}$ at $55^{\circ} \mathrm{C}$ with salmon sperm DNA as a supporter. Modified DNA samples were purified using the Wizard DNA Purification kit (Promega, Madison, WI, USA) according to the manufacturer's instructions. $\mathrm{NaOH}(1 \mathrm{M})$ was added and incubated for $7 \mathrm{~min}$ at room temperature to terminate the modification. The DNA was ethanol precipitated and dissolved in double distilled water for PCR.

$M S P$. Two primer sets were used to amplify the promoter region of the PTEN gene, which incorporated a number of $\mathrm{CpG}$ sites, one specific for the methylated sequence (M, 
Table II. Correlation between PTEN expression and breast cancer pathological characteristics.

\begin{tabular}{|c|c|c|c|c|c|c|c|c|c|c|}
\hline \multirow[b]{3}{*}{ Factors } & \multirow[b]{3}{*}{$\mathrm{n}$} & \multicolumn{8}{|c|}{ PTEN } & \multirow[b]{3}{*}{ P-value } \\
\hline & & \multicolumn{2}{|c|}{-} & \multicolumn{2}{|c|}{+} & \multicolumn{2}{|c|}{++} & \multicolumn{2}{|c|}{+++} & \\
\hline & & $\mathrm{n}$ & $\%$ & $\mathrm{n}$ & $\%$ & $\mathrm{n}$ & $\%$ & $\mathrm{n}$ & $\%$ & \\
\hline Age (years) & 146 & & & & & & & & & \\
\hline$<35$ & & 14 & 56.0 & 5 & 20.0 & 5 & 20.0 & 1 & 4.0 & 0.150 \\
\hline $35-55$ & & 38 & 40.0 & 27 & 28.4 & 18 & 18.9 & 12 & 12.6 & \\
\hline$>55$ & & 10 & 38.5 & 4 & 15.4 & 11 & 42.3 & 1 & 3.8 & \\
\hline Menopause & 146 & & & & & & & & & \\
\hline No & & 46 & 47.4 & 22 & 22.7 & 19 & 19.6 & 10 & 10.3 & 0.162 \\
\hline Yes & & 16 & 32.7 & 14 & 28.6 & 15 & 30.6 & 4 & 8.2 & \\
\hline T-stage & 146 & & & & & & & & & \\
\hline $\mathrm{T} 1$ & & 8 & 22.2 & 11 & 30.6 & 10 & 27.8 & 7 & 19.4 & 0.002 \\
\hline $\mathrm{T} 2$ & & 34 & 47.2 & 15 & 20.8 & 17 & 23.6 & 6 & 8.3 & \\
\hline $\mathrm{T} 3$ & & 12 & 52.2 & 5 & 21.7 & 5 & 21.7 & 1 & 4.3 & \\
\hline $\mathrm{T} 4$ & & 8 & 53.3 & 5 & 33.3 & 2 & 13.3 & 0 & 0.0 & \\
\hline Lymph node metastasis & 146 & & & & & & & & & \\
\hline No & & 18 & 38.3 & 11 & 23.4 & 12 & 25.5 & 6 & 12.8 & 0.630 \\
\hline Yes & & 45 & 45.5 & 25 & 25.3 & 22 & 22.2 & 7 & 7.1 & \\
\hline Stage & 146 & & & & & & & & & \\
\hline I & & 3 & 20.0 & 4 & 26.7 & 4 & 26.7 & 4 & 26.7 & 0.005 \\
\hline II & & 25 & 39.1 & 16 & 25.0 & 16 & 25.0 & 7 & 10.9 & \\
\hline III & & 28 & 47.5 & 15 & 25.4 & 13 & 22.0 & 3 & 5.1 & \\
\hline IV & & 6 & 75.0 & 1 & 12.5 & 1 & 12.5 & 0 & 0.0 & \\
\hline
\end{tabular}

Immunohistochemical reactivity graded according to the percentage of positive tumor cells:,$- 0 ;+,<20 ;++, 20-50 ;$ and,$+++>50 \%$.

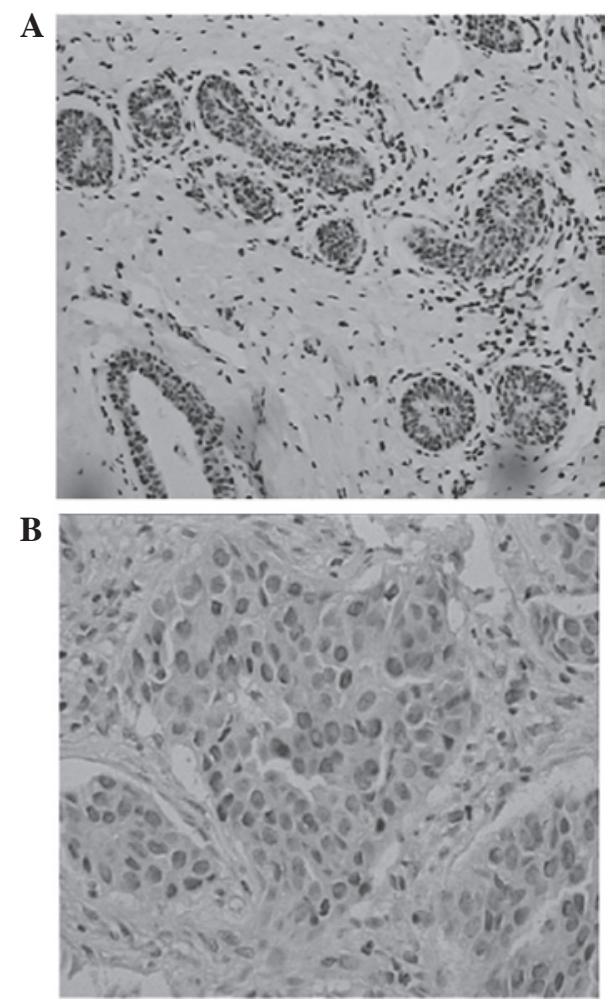

Figure 1. Expression of PTEN in breast tissues (A) closely adjacent to the carcinoma and (B) in the breast carcinoma. sense: 5'-TTCGTTCGTCGTCGTATTT-3'; antisense: 5'-GCCGCTTAACTCTAAACCGCAACCG-3'; PCR product, $206 \mathrm{bp}$ ) and the other for the unmethylated sequence (U, sense: 5'-TGTTGGTGGAGGTAGTTGTTT-3'; antisense: 5'-ACCACTTAACTCTAAACCACAACCA-3'; PCR product, $162 \mathrm{bp}$ ) (7). The primers used in the present study specifically detect the promoter sequence of the PTEN gene rather than that of the PTEN pseudogene. The PCR volume (50 $\mu \mathrm{l}$ ) included $200 \mathrm{ng}$ modified DNA, 20 pmol of each primer, $1.5 \mathrm{mmol} / 1 \mathrm{MgCl}_{2}, 5 \mu \mathrm{lPCR}$ intensifier and $2.5 \mathrm{U}$ HotStart Taq. The PCR parameters consisted of $64^{\circ} \mathrm{C}$ for 10 cycles, $62^{\circ} \mathrm{C}$ for 15 cycles and $60^{\circ} \mathrm{C}$ for 10 cycles, for $60 \mathrm{sec}$ at each temperature. Each MSP was repeated at least 3 times.

Statistical analysis. All comparisons between categorical variables were examined by the Fisher's exact chi-squared test. Association analysis was performed with the Spearman's rank correlation. Relapse-free survival was calculated using the Kaplan-Meier survival estimates and the log-rank test from the date of diagnosis until the last contact or relapse. A Cox regression analysis was performed to estimate the relative risks (with $95 \%$ confidence intervals). $\mathrm{P}<0.05$ was considered to indicate a statistically significant difference. Statistical analyses were conducted using SPSS 13.0 for Windows (SPSS, Inc., Chicago, IL, USA). 
Table III. PTEN expression and tumor immunophenotype (Spearmen's rank correlation)

\begin{tabular}{|c|c|c|c|c|c|c|c|c|c|c|}
\hline \multirow[b]{3}{*}{ Gene } & \multicolumn{8}{|c|}{ PTEN } & \multirow[b]{3}{*}{$\chi^{2}$} & \multirow[b]{3}{*}{ P-value } \\
\hline & \multicolumn{2}{|c|}{-} & \multicolumn{2}{|c|}{+} & \multicolumn{2}{|c|}{++} & \multicolumn{2}{|c|}{+++} & & \\
\hline & $\mathrm{n}$ & $\%$ & $\mathrm{n}$ & $\%$ & $\mathrm{n}$ & $\%$ & $\mathrm{n}$ & $\%$ & & \\
\hline \multicolumn{11}{|l|}{ ER } \\
\hline- & 21 & 42.9 & 16 & 32.7 & 12 & 24.5 & 0 & 0 & 2.303 & 0.023 \\
\hline+ & 32 & 48.5 & 15 & 22.7 & 12 & 18.2 & 7 & 10.6 & & \\
\hline++ & 7 & 35.0 & 3 & 15.0 & 6 & 30.0 & 4 & 20.0 & & \\
\hline+++ & 2 & 18.2 & 2 & 18.2 & 4 & 36.4 & 3 & 27.3 & & \\
\hline \multicolumn{11}{|l|}{ PR } \\
\hline- & 29 & 48.3 & 15 & 25.0 & 11 & 18.3 & 5 & 8.3 & 2.091 & 0.038 \\
\hline+ & 26 & 41.9 & 17 & 27.4 & 15 & 24.2 & 4 & 6.5 & & \\
\hline++ & 7 & 36.8 & 4 & 21.1 & 5 & 26.3 & 3 & 15.8 & & \\
\hline+++ & 0 & 0.0 & 0 & 0.0 & 3 & 60.0 & 2 & 40.0 & & \\
\hline \multicolumn{11}{|c|}{ HER-2 } \\
\hline- & 34 & 46.6 & 15 & 20.5 & 16 & 21.9 & 8 & 11.0 & 0.081 & 0.865 \\
\hline+ & 11 & 32.4 & 8 & 23.5 & 9 & 26.5 & 6 & 17.6 & & \\
\hline++ & 10 & 37.0 & 12 & 44.4 & 5 & 18.5 & 0 & 0.0 & & \\
\hline+++ & 7 & 58.3 & 1 & 8.3 & 4 & 33.3 & 0 & 0.0 & & \\
\hline
\end{tabular}

Immunohistochemical reactivity graded according to the percentage of positive tumor cells:,$- 0 ;+,<20 ;++, 20-50 ;$ and,$+++>50 \%$. ER, estrogen receptor; PR, progesterone receptor.

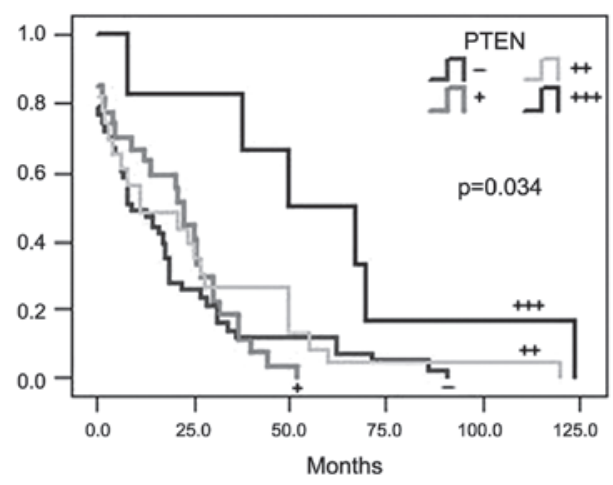

Figure 2. PTEN expression and relapse free survival of breast cancer; lines indicate patients with various levels of PTEN expression. The high expression of PTEN was significantly associated with a longer relapse-free survival.

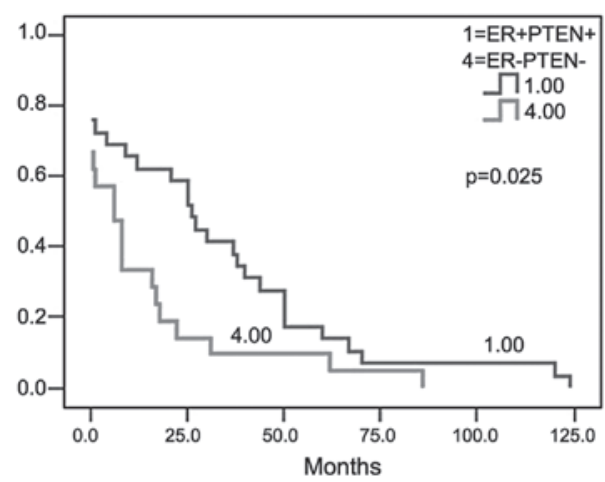

Figure 3. ER + PTEN expression and disease-free survival of breast cancer. The longest relapse-free survival occurred in patients that were ER and PTEN positive. ER, estrogen receptor.

\section{Results}

PTEN expression in breast cancer. PTEN was markedly expressed in the cytoplasm and nuclei of the breast cancer cells and in the normal duct epithelial cells (Fig. 1). PTEN-positive cells were diffusely distributed in the carcinoma. The positive expression rate of PTEN was 57.5\% (84/146) in the breast cancer patients, but $100 \%$ in the normal breast tissues closely adjacent to the carcinoma (Table II).

The correlation between PTEN expression and the clinicopathological parameters, including age, disease stage, lymph node status, tumor grade, size and expression of ER, PR and Her-2/neu, was analyzed. The results revealed a negative

correlation between PTEN expression and the tumor size or stage. However, no correlation was observed between PTEN expression and age, menopause or the presence of lymph node metastasis (Table II).

PTEN expression and tumor immunophenotype. The correlation between PTEN expression and tumor immunophenotype was also analyzed and the results demonstrated that there was no correlation between PTEN expression and Her-2/neu $(\mathrm{P}=0.865)$. However, there was a positive correlation between the expression of PTEN and ER $(\mathrm{P}=0.023)$ or $\mathrm{PR}(\mathrm{P}=0.038$; Table III). 
Table IV. Cox regression analysis estimated prognostic value by hazard ratios and $95 \%$ CI for relapse-free survival

\begin{tabular}{|c|c|c|c|c|c|c|c|}
\hline \multirow[b]{2}{*}{ Variable } & \multirow[b]{2}{*}{$\mathrm{B}$} & \multirow[b]{2}{*}{ SE } & \multirow[b]{2}{*}{ Wald } & \multirow[b]{2}{*}{ P-value } & \multirow[b]{2}{*}{$\operatorname{Exp}(B)$} & \multicolumn{2}{|c|}{$95 \%$ CI for $\operatorname{Exp}(\mathrm{B})$} \\
\hline & & & & & & Lower & Upper \\
\hline Age & 0.190 & 0.348 & 0.298 & 0.585 & 1.209 & 0.611 & 2.393 \\
\hline Menopause & 0.779 & 0.303 & 6.596 & 0.010 & 2.180 & 1.203 & 3.951 \\
\hline Tumor size & 0.836 & 0.202 & 17.077 & 0.000 & 2.306 & 1.552 & 3.428 \\
\hline Lymph node & 0.806 & 0.312 & 6.673 & 0.010 & 2.238 & 1.215 & 4.125 \\
\hline Adjunct therapy & -0.796 & 0.332 & 5.757 & 0.016 & 0.451 & 0.235 & 0.864 \\
\hline ER & -0.793 & 0.334 & 5.636 & 0.018 & 0.453 & 0.235 & 0.871 \\
\hline PR & 0.440 & 0.322 & 1.861 & 0.173 & 1.552 & 0.825 & 2.918 \\
\hline HER & -1.141 & 0.373 & 9.328 & 0.002 & 0.320 & 0.154 & 0.665 \\
\hline PTEN & -0.241 & 0.142 & 2.893 & 0.089 & 0.786 & 0.595 & 1.037 \\
\hline
\end{tabular}

B, partial regression coefficent; SE, standard error; Wald, statistical magnitude; Exp (B), relative risk; CI, confidence interval; ER, estrogen receptor; PR, progesterone receptor.

A

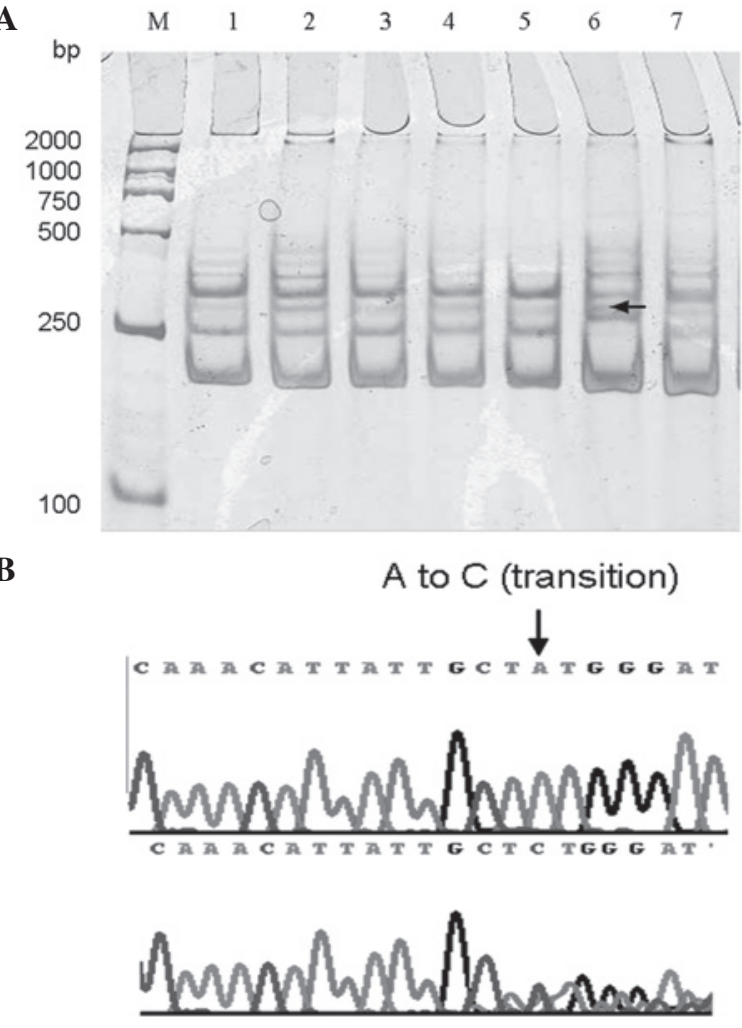

Figure 4. (A) Single-strand conformation polymorphism (SSCP) and sequencing analysis of PTEN mutation. Amplified DNA fragments from exons 1-9 of the PTEN gene from tumor tissues and normal tissues adjacent to the tumor. The mobility band shift was present in the polymerase chain reaction (PCR) product of the tumor DNA sample in exon 2 (arrow), indicating a conformational change in the DNA fragment (lane 6). (B) Sequence analysis of the PCR product from exon 2 of the PTEN gene. The arrow indicates a nucleotide change in codon 24 , which resulted in a change from methionine to leucine. M, marker.

PTEN expression and relapse-free survival. Breast cancer patients (98/101) were followed up for 40-266 months (median, 103 months; 3 patients were missed). A univariate analysis revealed that the high expression of PTEN was significantly associated with a longer relapse-free survival $\left(\chi^{2}=7.965\right.$;

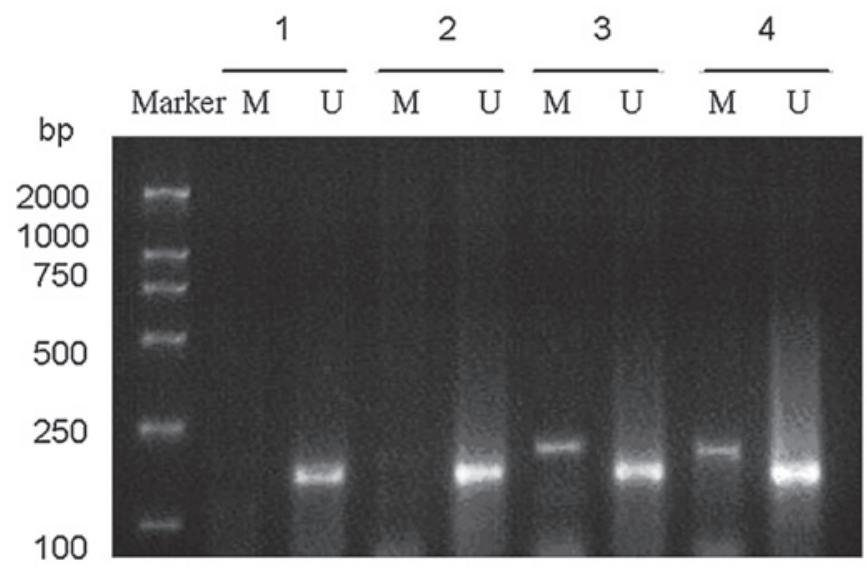

Figure 5. PTEN promoter CpG MSP product. Marker, 100-2000 bp. 1, normal control; 2, breast carcinoma, no PTEN methylation; 3 and 4, breast carcinoma, PTEN methylation. M, PTEN methylation; U, PTEN unmethylation; MSP, methylation specific polymerase chain reaction.

$\mathrm{P}=0.034$; Fig. 2). The longest relapse-free survival occurred in patients that were ER- and PTEN-positive $\left(\chi^{2}=5.044 ; \mathrm{P}=0.025\right.$; Fig. 3). A Cox regression analysis demonstrated that as the prognostic factors, including menopausal status ( $\mathrm{r}=0.779$; $\mathrm{P}=0.010)$, tumor size $(\mathrm{r}=0.836 ; \mathrm{P}=0.000)$, lymph nodes status $(\mathrm{r}=0.806 ; \mathrm{P}=0.010)$, adjuvant therapy $(\mathrm{r}=-0.796 ; \mathrm{P}=0.016)$ and expression of ER ( $\mathrm{r}=-0.793$; $\mathrm{P}=0.018)$ and HER-2 ( $\mathrm{r}=1.141$; $\mathrm{P}=0.002)$, were introduced into the equation, there was no correlation between the expression of PTEN and relapse-free survival (Table IV).

PTEN mutation in breast cancer. SSCP analysis identified no abnormal single-strand conformation in the 10 normal tissues adjacent to the tumor. Among the 45 fresh breast carcinoma samples, 3 band shifts were identified by PCR-SSCP (Fig. 4). However, only 1 mutation was confirmed in exon 2 by sequencing. The PTEN mutation rate was $2.2 \%(1 / 45)$. Sequencing analysis revealed that a codon $24 \mathrm{~A} \rightarrow \mathrm{C}$ missense mutation in exon 2 resulted in a codogenic amino acid change from methionine to leucine (Fig. 4). 
Table V. Clinicopathological features, PTEN expression and promoter methylation in breast carcinoma.

\begin{tabular}{|c|c|c|c|c|c|}
\hline \multirow[b]{2}{*}{ Groups } & \multirow[b]{2}{*}{ Total cases (n) } & \multicolumn{2}{|c|}{ Methylation of PTEN } & \multirow[b]{2}{*}{$\chi^{2}$} & \multirow[b]{2}{*}{ P-value } \\
\hline & & $\mathrm{n}$ & $\%$ & & \\
\hline \multicolumn{6}{|c|}{ PTEN expression } \\
\hline- & 18 & 9 & 50.0 & \multirow[t]{2}{*}{4.994} & \multirow[t]{2}{*}{0.025} \\
\hline+ & 27 & 5 & 18.5 & & \\
\hline \multicolumn{6}{|c|}{ Lymph node } \\
\hline- & 18 & 5 & 27.8 & \multirow[t]{2}{*}{0.733} & \multirow[t]{2}{*}{0.392} \\
\hline+ & 27 & 9 & 33.3 & & \\
\hline \multicolumn{6}{|l|}{ Stage } \\
\hline I & 7 & 1 & 14.3 & \multirow[t]{3}{*}{1.425} & \multirow[t]{3}{*}{0.490} \\
\hline II & 21 & 8 & 38.1 & & \\
\hline III & 17 & 5 & 29.4 & & \\
\hline \multicolumn{6}{|l|}{ T stage } \\
\hline $\mathrm{T} 1$ & 15 & 3 & 20.0 & \multirow[t]{3}{*}{2.118} & \multirow[t]{3}{*}{0.347} \\
\hline $\mathrm{T} 2$ & 24 & 10 & 41.7 & & \\
\hline $\mathrm{T} 3$ & 6 & 1 & 16.7 & & \\
\hline \multicolumn{6}{|l|}{ ER } \\
\hline - & 25 & 6 & 24.0 & \multirow[t]{2}{*}{0.249} & \multirow[t]{2}{*}{1.327} \\
\hline+ & 20 & 8 & 40.0 & & \\
\hline \multicolumn{6}{|c|}{ HER-2 expression } \\
\hline Low & 33 & 11 & 33.3 & \multirow[t]{2}{*}{0.285} & \multirow[t]{2}{*}{0.593} \\
\hline High & 12 & 3 & 25.0 & & \\
\hline
\end{tabular}

+, positive; -, negative; ER, estrogen receptor.

PTEN promoter methylation in breast cancer and its correlation with clinical manifestations. The results of the MSP analysis of PTEN promoter methylation in the 45 breast cancer patients are summarized in Table V and presented in Fig. 5.

The MSP analysis demonstrated that PTEN promoter methylation was detected in 14 breast cancer cases with a methylation rate of $31.1 \%$ (14/45; Table V and Fig. 5). Among the cases with PTEN promoter methylations, 64.3\% (9/14) of the patients lost PTEN expression. The occurrence of PTEN promoter methylation in the patients with negative PTEN expression was significantly higher that in the PTEN-positive cases $\left(\chi^{2}=4.994 ; \mathrm{P}=0.025\right.$; Table $\mathrm{V}$ and Fig. 5).

Further clinicopathological analysis revealed that among the 14 cases with positive PTEN promoter methylation, $7.1 \%$ $(1 / 14)$ were stage I breast cancer, 64.3\% (9/14) had axillary lymph node metastasis, $42.9 \%$ (6/14) were ER-negative and $21.4 \%$ (3/14) overexpressed HER-2. However, these cases were not found to be significantly different compared with the PTEN methylation negative group $(\mathrm{P}>0.05)$.

\section{Discussion}

PTEN was the first recognized tumor suppressor with lipid phosphatase activity. A previous study (3) demonstrated that PTEN is mutated or inactivated in a number of malignant tumors, including neuroglioma, endometrial, prostate, breast, thyroid and liver cancer. Mutation rates range between 40 and $80 \%$ in prostatic cancer, endometrial carcinoma and advanced neuroglioma, indicating that the PTEN mutation is important for tumorigenesis and cancer development (3). The majority of PTEN mutations in tumors are localized to exons 5, 7 or $8(5,7,8)$. In CS, $40 \%$ of PTEN mutations are located in the exon 5 phosphatase-coding domain, leading to a reduction in its tumor suppressor activity.

In breast cancer, a 10-40\% loss of heterozygosity ( $\mathrm{LOH})$ has been identified at the chromosome 10q23 region that contains the PTEN gene $(6,8,9)$. $\mathrm{LOH}$ at the $10 \mathrm{q} 23$ region is functionally associated with the occurrence of breast cancer and this region has also been found to significantly correlate with tumor characteristics. In the study by Garcia et al, the breast cancer patients with $\mathrm{LOH}$ were younger, exhibiting a high incidence of lymph node metastases and a high histological grade (10). The loss of 10q23 is markedly associated with tumor progression (9). $\mathrm{LOH}$ was not observed in pure intraductal carcinomas, while it was observed in $40 \%$ (17/42) of the invasive carcinomas. LOH at 10q23 was found to correlate with the loss of ER (10).

Although LOH at $10 \mathrm{q} 23$ is frequent, the somatic PTEN mutation rate is $<5 \%$ (3) and the majority of PTEN gene mutations occur in advanced and metastatic breast cancer. The association between PTEN and breast cancer is controversial and it has been hypothesized that another new gene is located in the $10 \mathrm{q} 23$ region. Further studies have indicated that a reduced 
PTEN expression rate occurs in $83 \%$ of breast cancer cases (11). The frequency of reduced PTEN expression in invasive cancer was higher than that in the carcinoma in situ (12). It was demonstrated that reduced PTEN expression was correlated with a loss of ER expression, tumor size and lymph node metastasis. Therefore, PTEN may represent an important prognostic factor.

In the present study, the expression rate of PTEN in breast carcinoma $(57.5 \%, 84 / 146)$ was found to be significantly lower than that of normal breast tissues adjacent to tumors $(100 \%$, $10 / 10 ; \mathrm{P}<0.05)$. In addition, PTEN expression was found to significantly correlate with tumor size or stage, indicating that the reduced expression of PTEN was associated with a larger tumor size or advanced stages. In addition, PTEN expression was found to correlate with ER or PR. A survival analysis revealed that the 2-year relapse-free survival rate of breast cancer patients with PTEN expression grade +++ was higher than those with lower grades of PTEN expression. The lowest rate of breast cancer relapse-free survival occurred in ER- and PTEN-negative patients. Consistent with studies by Perren et al (11) and Depowski et al (13), PTEN did not enter the equation of the COX regression analysis in the present study. By contrast, other studies have reported that PTEN is an independent prognostic factor $(14,15)$.

PCR-SSCP and sequencing analysis detected only 1 mutation in 45 breast cancer patients and this point mutation was a missense mutation in exon 2. The patient with the PTEN mutation had a high risk of recurrence, infiltrating duct carcinoma, a tumor size of $1.2 \times 2.0 \times 2.0 \mathrm{~cm}$ and axillary lymph node metastasis (4/10). In addition, this patient was at the pathological stage of pT1N2M0, IIIA, ER -, PR - and Her2 ++. In the present study, the loss of PTEN expression was observed in $42.5 \%(62 / 146)$ of patients, while the mutation rate was only $2.2 \%(1 / 45)$, indicating that mechanisms other than mutation caused the loss of PTEN expression.

Shoman et al (15) previously demonstrated that reduced PTEN expression was associated with the shorter relapse-free survival of 100 tamoxifen-treated ER-positive breast cancer patients. When stage I patients were analyzed separately, reduced PTEN expression was a strong predictor of shorter relapse-free and disease-specific survival. When patients were stratified by levels of ER expression ( $\geq 50 \%$ vs. $<50 \%$ positive cells), reduced PTEN expression was associated with a less favorable outcome in each patient group. Among the tumor patients with a normal expression of PTEN, $30 \%$ relapsed and $25 \%$ succumbed to their condition. By contrast, among the tumor patients with a reduced expression of PTEN, $90 \%$ relapsed and $65 \%$ succumbed to their condition. However, in this earlier study, ER-negative breast cancer cases and patients not treated with tamoxifen were not included. This study and the results of the present study indicate a correlation between PTEN and ER, and the combination of PTEN and ER may predict an outcome for breast cancer patients.

Estrogen-induced proliferation of mammary and uterine epithelial cells is primarily mediated by ER via estrogen-independent (AF-1) and estrogen-dependent (AF-2) activation domains. These domains regulate gene transcription by recruiting co-activators and interacting with the general transcriptional machinery. In vitro studies have demonstrated that phosphatidylinositol 3-kinase (PI3K) and AKT activate ER in the absence of estrogen (16). PI3K was shown to increase the activities of the AF-1 and AF-2 domains of ER, while AKT increased the activity of the AF-1 domain only. PTEN and a catalytically inactive AKT are able to downregulate PI3K-induced AF-1 activity, indicating that PI3K activates ER via AKT-dependent and -independent pathways. It has been demonstrated that the activation of the PI3K/AKT survival pathways and the hormone-independent activation of ER are associated with the inhibition of tamoxifen-induced apoptotic regression. AKT protects breast cancer cells from tamoxifen-induced apoptosis. The downregulation of PTEN expression results in a loss of the inhibition of PI3K/AKT. By contrast, the high expression of PTEN improves the response of breast cancer to tamoxifen. Therefore, breast cancer patients with a positive expression of PTEN and ER are associated with longer survival (16).

In addition to gene mutation, epigenetic regulation, including promoter hypermethylation, has been demonstrated to alter tumor suppressor gene expression and contribute to tumorigenesis. Thus, the methylation status of the PTEN promoter CpG island was analyzed in the present study. As one of the most recurrent gene alterations, DNA methylation significantly affects chromosomal formation, gene expression and DNA replication $(17,18)$. $\mathrm{CpG}$ islands in the promoter or nearby regions are frequently methylated, leading to the silencing of gene transcription. Methylation of a growing number of tumor suppressor genes, including p16, APC, MLH1 and BRCA1, has been revealed to be one of the most frequent mechanisms of gene transcription inactivation and loss of gene function. Soria et al (19) analyzed the methylation of the PTEN promoter and the PTEN expression in 30 cases of non-small cell lung cancer (NSCLC). The results indicated that PTEN methylation occurred in 35\% (7/20) of NSCLC cases and 69\% (11/16) of NSCLC cell lines. In addition, PTEN methylation was not detected in patients with positive PTEN expression. Thus, the loss of PTEN expression was reported to correlate with the methylation of its promoter. PTEN methylation was considered as one of main causes of loss of PTEN expression. In the present study, PTEN methylation was detected in $31.1 \%(14 / 45)$ of breast cancer cases. Among these, 14 tissues with PTEN methylation, 64.3\% (9/14), exhibited a loss of PTEN expression. The PTEN promoter methylation rate was $50 \%(9 / 18)$ in the PTEN-negative cases, which is statistically different from the rate in the PTEN-positive cases $(18.5 \%, 5 / 27 ; \mathrm{P}=0.025)$. Therefore, none of the normal breast tissues adjacent to the tumor were found to exhibit methylated PTEN promoters. These results are consistent with a previous study (20) demonstrating that PTEN methylation occurred in $34 \%$ of cases of breast invasive ductal cancer and that $60 \%$ of these were found to exhibit a loss of PTEN expression. In addition, none of the breast cancer cell lines and normal breast tissues were observed to have PTEN methylation. These results indicated that the methylation of the PTEN promoter may result in PTEN inactivation in breast cancer.

Previous studies have demonstrated that the $\mathrm{PI} 3 \mathrm{~K} / \mathrm{AKT}$ /PTEN pathway is important for tumorigenesis. The PI3K signaling pathway is associated with almost all aspects of tumor biology, including cell transformation, growth, proliferation, migration and apoptosis evasion and genomic instability, angiogenesis, metastasis and cancer stem cell maintenance $(21,22)$. PTEN degrades the product PI3K by dephosphorylating phosphatidylinositol 3,4,5-trisphosphate and phosphatidylinositol 3,4-bisphosphate at the 3 ' position (23). The loss of function or reduced expression of PTEN leads to the accu- 
mulation of critical messenger lipids, which in turn increases AKT phosphorylation and activity, leading to decreased apoptosis and/or increased mitogen signaling (24-28). However, although the PI3K/AKT/PTEN pathway contains a number of attractive therapeutic targets, clinical trials of pathway-targeted drugs have not proved as promising as expected. It is possible that a novel signaling pathway playing a significant role in the $\mathrm{PI} 3 \mathrm{~K} / \mathrm{AKT}$ /PTEN pathway has yet to be identified or that present markers are not sufficient to assess therapeutic response (29-30).

\section{References}

1. Tamura M,Gu J,Matsumoto K, Aota S,Parsons R and Yamada KM Inhibition of cell migration, spreading, and focal adhesions by tumor suppressor PTEN. Science 280: 1614-1617, 1998.

2. Waite KA and Eng C: Protean PTEN: form and function. Am J Hum Genet 70: 829-844, 2002.

3. Lu Y, Lin YZ, LaPushin R, Cuevas B, Fang X, Yu SX, Davies MA, Khan H, Furui T, Mao M, Zinner R, Hung MC, Steck P, Siminovitch K and Mills GB: The PTEN/MMAC1/TEP tumor suppressor gene decreases cell growth and induces apoptosis and anoikis in breast cancer cells. Oncogene 18: 7034-7045, 1999.

4. Weng LP, Brown JL and Eng C: PTEN coordinates (G1) arrest by down-regulating cyclin D1 via its protein phosphatase activity and up-regulating p27 via its lipid phosphatase activity in a breast cancer model. Hum Mol Genet 10: 599-604, 2001.

5. Tamguney T and Stokoe D: New insights into PTEN. J Cell Sci 120: 4071-4079, 2007.

6. Marsh DJ, Coulon V, Lunetta KL, Rocca-Serra P, Dahia PL, Zheng Z, Liaw D, Caron S, Duboué B, Lin AY, Richardson AL, Bonnetblanc JM, Bressieux JM, Cabarrot-Moreau A, Chompret A, Demange L, Eeles RA, Yahanda AM, Fearon ER, Fricker JP, Gorlin RJ, Hodgson SV, Huson S, Lacombe D, Eng C et al: Mutation spectrum and genotype-phenotype analyses in Cowden disease and Bannayan-Zonana syndrome, two hamartoma syndromes with germline PTEN mutation. Hum Mol Genet 7: 507-515, 1998.

7. Baeza N, Weller M, Yonekawa Y, Kleihues P and Ohgaki H: PTEN methylation and expression in glioblastomas. Acta Neuropathol 106: 479-485, 2003.

8. Freihoff D, Kempe A, Beste B, Wappenschmidt B, Kreyer E, Hayashi Y, Meindl A, Krebs D, Wiestler OD, von Deimling A and Schmutzler RK: Exclusion of a major role for the PTEN tumour-suppressor gene in breast carcinomas. Br J Cancer 79: 754-758, 1999.

9. Bose S, Wang SI, Terry MB, Hibshoosh $\mathrm{H}$ and Parsons R: Allelic loss of chromosome 10q23 is associated with tumor progression in breast carcinomas. Oncogene 17: 123-127, 1998

10. Garcia JM, Silva JM, Dominguez G, Gonzalez R, Navarro A, Carretero L, Provencio M, España P and Bonilla F: Allelic loss of the PTEN region (10q23) in breast carcinomas of poor pathophenotype. Breast Cancer Res Treat 57: 237-243, 1999.

11. Perren A, Weng LP, Boag AH, Ziebold U, Thakore K, Dahia PL, Komminoth P, Lees JA, Mulligan LM, Mutter GL and Eng C: Immunohistochemical evidence of loss of PTEN expression in primary ductal adenocarcinomas of the breast. Am J Pathol 155: 1253-1260, 1999.

12. Bose S, Crane A, Hibshoosh H, Mansukhani M, Sandweis L and Parsons R: Reduced expression of PTEN correlates with breast cancer progression. Hum Pathol 33: 405-409, 2002.

13. Depowski PL, Rosenthal SI and Ross JS: Loss of expression of the PTEN gene protein product is associated with poor outcome in breast cancer. Mod Pathol 14: 672-676, 2001.
14. Lee JS, Kim HS, Kim YB, Lee MC, Park CS and Min KW: Reduced PTEN expression is associated with poor outcome and angiogenesis in invasive ductal carcinoma of the breast. Appl Immunohistochem Mol Morphol 12: 205-210, 2004.

15. Shoman N, Klassen S, McFadden A, Bickis MG, Torlakovic E and Chibbar R: Reduced PTEN expression predicts relapse in patients with breast carcinoma treated by tamoxifen. Mod Pathol 18: 250-259, 2005.

16. CampbellRA,Bhat-NakshatriP,PatelNM,Constantinidou D,AliS and Nakshatri H: Phosphatidylinositol 3-kinase/AKT-mediated activation of estrogen receptor alpha: a new model for anti-estrogen resistance. J Biol Chem 276: 9817-9824, 2001.

17. Keshet I, Lieman-Hurwitz J and Cedar H: DNA methylation affects the formation of active chromatin. Cell 44: 535-543, 1986.

18. Antequera F: Structure, function and evolution of $\mathrm{CpG}$ island promoters. Cell Mol Life Sci 60: 1647-1658, 2003.

19. Soria JC, Lee HY, Lee JI, Wang L, Issa JP, Kemp BL, Liu DD, Kurie JM, Mao L and Khuri FR: Lack of PTEN expression in non-small cell lung cancer could be related to promoter methylation. Clin Cancer Res 8: 1178-1184, 2002.

20. Khan S, Kumagai T, Vora J, Bose N, Sehgal I, Koeffler PH and Bose S: PTEN promoter is methylated in a proportion of invasive breast cancers. Int J Cancer 112: 407-410, 2004.

21. Shaw RJ and Cantley LC: Ras, PI(3)K and mTOR signalling controls tumour cell growth. Nature 441: 424-430, 2006.

22. Janzen V and Scadden DT: Stem cells: good, bad and reformable. Nature 441: 418-419, 2006.

23. Simpson L and Parsons R: PTEN: life as a tumor suppressor. Exp Cell Res 264: 29-41, 2001.

24. Dudek H, Datta SR, Franke TF, Birnbaum MJ, Yao R, Cooper GM, Segal RA, Kaplan DR and Greenberg ME: Regulation of neuronal survival by the serine-threonine protein kinase Akt. Science 275: 661-665, 1997.

25. Ramaswamy S, Nakamura N, Vazquez F, Batt DB, Perera S, Roberts TM and Sellers WR: Regulation of G1 progression by the PTEN tumor suppressor protein is linked to inhibition of the phosphatidylinositol 3-kinase/Akt pathway. Proc Natl Acad Sci USA 96: 2110-2115, 1999.

26. Stahl JM, Sharma A, Cheung M, Zimmerman M, Cheng JQ, Bosenberg MW, Kester M, Sandirasegarane L and Robertson GP: Deregulated Akt3 activity promotes development of malignant melanoma. Cancer Res 64: 7002-7010, 2004.

27. Curtin JA, Fridlyand J, Kageshita T, Patel HN, Busam KJ, Kutzner H, Cho KH, Aiba S, Bröcker EB, LeBoit PE, Pinkel D and Bastian BC: Distinct sets of genetic alterations in melanoma. N Engl J Med 353: 2135-2147, 2005.

28. Lian Z and Di Cristofano A: Class reunion: PTEN joins the nuclear crew. Oncogene 24: 7394-7400, 2005.

29. Miller TW, Pérez-Torres M, Narasanna A, Guix M, Stål O, Pérez-Tenorio G, Gonzalez-Angulo AM, Hennessy BT, Mills GB, Kennedy JP, Lindsley CW and Arteaga CL: Loss of phosphatase and tensin homologue deleted on chromosome 10 engages ErbB3 and insulin-like growth factor-I receptor signaling to promote antiestrogen resistance in breast cancer. Cancer Res 69: 4192-4201, 2009.

30. Saal LH, Johansson P, Holm K, Gruvberger-Saal SK, She QB, Maurer M, Koujak S, Ferrando AA, Malmström P, Memeo L, Isola J, Bendahl PO, Rosen N, Hibshoosh H, Ringnér M, Borg $\mathrm{A}$ and Parsons R: Poor prognosis in carcinoma is associated with a gene expression signature of aberrant PTEN tumor suppressor pathway activity. Proc Natl Acad Sci USA 104: 7564-7569, 2007. 